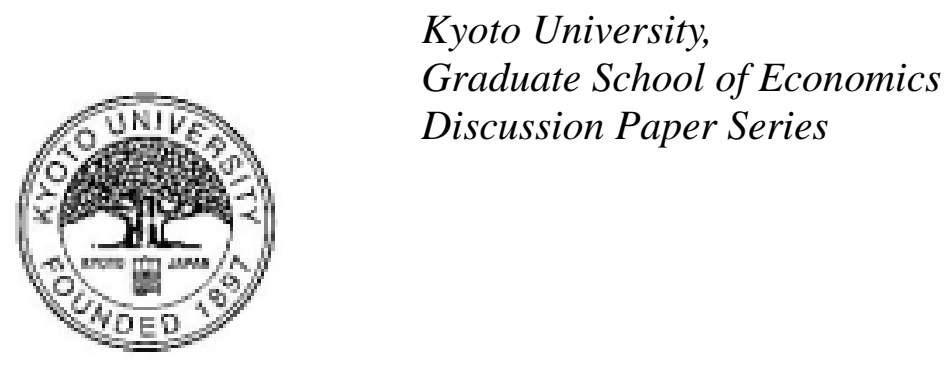

Just ETS?

Social Justice and Recent Reforms in EU and US Carbon Markets

Sven Rudolph and Achim Lerch

Discussion Paper No. E-15-009
Graduate School of Economics
Kyoto University
Yoshida-Hommachi, Sakyo-ku
Kyoto City, 606-8501, Japan

November, 2015 


\section{JUST ETS? \\ SOCIAL JUSTICE AND RECENT REFORMS IN EU AND US CARBON MARKETS ${ }^{i}$ \\ Sven Rudolph, Achim Lerch ${ }^{\mathrm{ii}}$}

\section{Introduction}

Besides environmental effectiveness and economic efficiency, social justice plays a key role in sustainable climate policy. Social justice was a founding principle of sustainable development (WCED 1987) and recent empirical research has proven the appreciation people in different countries show for an equitable approach to climate policy (Schleich et al. 2014). In addition, current energy transformation debates have raised questions on a fair burden sharing, especially because even an efficient policy mix is expected to increase overall costs (Heindl et al. 2014).

While still not the dominating force, carbon pricing has become more popular (World Bank 2015), and most certainly, in order to keep compliance costs to a minimum, market-based instruments must lead the way. Recently, cap-and-trade schemes have spread across the world, and while still notable design differences exist, linking domestic schemes continues to be a relevant supplement to global climate action (Ranson/Stavins 2015). The EU still operates the flagship supra-national carbon market, but US regions are picking up with cross-state schemes. The EU Emissions Trading System (EU ETS) and the Regional Greenhouse Gas Initiative (RGGI), are of particular interest as, after heavy critique, they have undergone fundamental constructive reforms. Still, carbon market design has considerable justice implications, which, other than environmental and economic issues, have been widely neglected in research and policy.

Hence, we ask: What are thorough social justice criteria for carbon market design. To what extent do early schemes on both sides of the Atlantic fulfill these criteria? And have recent reforms made these schemes more socially just? We answer the questions, by using normative concepts from modern climate justice theory in order to derive criteria for socially just carbon markets. We then apply them to carbon market design in the EU and the US. We mainly argue that, as a socially just design is basically possible, justice criteria must be considered thoroughly in carbon market design. So far, even after improvements by recent reforms, existing EU and US markets only partly fulfill ambitious social justice criteria, but further improvements are possible. 


\section{What's just in carbon market design?}

\subsection{Social justice concepts}

The concept of social justice has been controversially debated for hundreds of years, but still opinions differ on the question if social justice can be defined in abstract terms and how it can be applied to climate policy issues. Indeed, while some scholars still believe social justice to be a concept of competing claims and case-by-case negotiations, even competing claims can be logically discriminated against, and priorities can be defined on social justice grounds without ethically discriminating against individuals (Ott/Döring 2004). Global warming, in turn, represents one of mankind's most pressing challenges with immediate social justice implications: Climate change strongly influences the livelihood of current and future generations, distributional decisions have so far not been sufficiently based on historic or geographical responsibilities, and carbon markets even distribute implicit private property rights to the use of the commonly owned atmosphere. Hence, defining abstract criteria for social justice criteria and thoroughly considering climate policy and carbon market design implications seems feasible and highly desirable.

With climate policy and carbon market design in mind, the following social justice concepts immediately apply (Helmstädter 1997, Krebs 2000, Lerch 2003): First, the concepts of procedural justice and result-based distributional justice can be differentiated. Procedural justice implies that only procedures and rules of social processes can be just, while result-based justice refers to fair outcomes of social processes. Critics state that referring to the concept of result-based justice alone implies presumptuousness with respect to the availability and manageability of knowledge (Nozick 1974, Hayek 1996); it would dictate an abstract distributional result independent of its genesis. However, using some notion of the concept of result-based distributional justice is indispensable already on theoretical grounds; in addition to that, economic psychology studies show that individuals base their economic decisions on result-based concepts of fairness rather than on procedures alone (Kahnemann/Knetsch/Thaler 1986).

Within the concept of result-based distributional justice, justice in transfer and acquisition, justice within allocation, and redistributive justice can be distinguished (Helmstädter 1997). Justice in transfer and acquisition demands, that an effort is compensated by an equivalent service; 
a requirement inherently fulfilled by market transactions. Justice within allocation, in contrast, asks for a fair distribution of goods according to individual claims. Redistributive justice, refers to a fair outcome of redistributive procedures subsequent to market allocations.

The necessary acceptance of the latter two concepts, however, raises the question on what the criteria for (re-)distribution should be. Welfare-based justice calls for a fair distribution to be based on individuals' needs, while desert-based justice requires it to be based on each individual's share of contribution in the production of a good. Desert-based justice is thus faced with at least two serious problems: First, effort can be measured either in input or in output terms. Second, with respect to natural resources, even if their appropriation is legitimate due to the fact that it needs human labor in addition to nature's services, still, a relevant part of the result is provided by nature. A combination of desert-based and welfare-based justice - "from each according to his ability, to each according to his needs” implicitly proposed by Marx (1972), however, does not set proper economic incentives. Rawls (1971), in turn, proposed a more promising combination of the two concepts, which will be discussed later.

But does a fair distribution necessarily imply an equal distribution? In the "why equality"debate (Krebs 2000) egalitarianism is strongly challenged, and inviolable standards such as human dignity are proposed as alternatives. But while equality certainly cannot be considered the sole criterion for social justice, and it anyway has to be accompanied by minimum standards, preferring equality to inequality seems theoretically adequate (Ott/Döring 2004) and empirically justified (Schleich et al. 2014). But even if equality is accepted, the "equality of what"-question arises. Reference points proposed in the literature are e.g. preferences and talents not under individual control (Sen), basic rights (Nozick), or income (Daly). While a naïve notion of equality in terms of equal welfare for everybody is obviously inadequate, Rawls (1971) called for equality in terms of rights and freedom as well as chances and opportunities. Inequalities, however, can only be accepted for income and capital, if, and only if, they provide the highest benefit to the poorest - compared to a situation of equality, in which the poorest benefit less -, and, if offices and positions are equally open to everybody (difference principle). 
Last, for sustainability, the Brundtland Report (WCED 1987) emphasized that the needs of both current and future generations should be taken into account. While intra-generational justice refers to the distribution within one current generation - e.g. on the national (rich vs. poor citizens) or international (industrialized vs. less developed countries) level -, inter-generational justice accounts for distributional issues between present and future generations.

This variety of social justice aspects certainly makes deriving concrete design recommendations for carbon markets quite a challenge. But as questions on economically efficient and environmentally effective climate policy cap-and-trade schemes have been discussed in detail before (Fankhauser/Hepburn 2010), and social justice remains the blind spot of sustainable carbon markets (Rudolph et al. 2012), we now apply social justice to carbon market design (Harris 2010, Lerch 2011, Ott/Sachs 2002,).

\subsection{Social justice in carbon market design}

To begin with, following the concept of result-based distributional justice, we need to look at the concrete carbon market design. It is obvious that establishing a fair climate policy and carbon market negotiation procedure alone, e.g. under the United Nations or democratically elected national governments, is not sufficient for calling a carbon market socially just. We have to thoroughly consider the outcome, in this case the detailed carbon market design, itself.

Such a carbon market, should cover all pollutants and make participation mandatory for all polluters, because only full coverage and compulsory participation would fulfill the equality, the intra- and inter-generational justice, and the polluter-pays-principle. The polluter-pays principle reflects desert-based justice and allows for taking into account historic responsibilities for climate change. If only selected greenhouse gases (GHG) would be covered, first, emitters of covered gases would be disadvantaged compared to those emitting non-covered gases, which would both violate the intra-generational justice and the equality criterion. Second, this exemption would leave some pollutants unregulated, which might hurt future generations' rights. Excluding some GHG would only be justifiable if the reliability of monitoring is questionable or if monitoring costs are prohibitive. Exempting selected polluters would have the same detrimental effects on social justice as excluding certain pollutants and the polluter-pays-principle would also be 
violated. Obligatory participation alone would guarantee compliance with reduction targets and the complete emission cost payment by all relevant polluters thus complying with intergenerational justice, the polluter-pays principle, and the equality criterion. As a design consequence, social justice calls for an upstream carbon market, which covers emissions at the level of entry into the economy (e.g. fossil fuel producers or importers), instead of a downstream scheme, which covers pollutants at the actual point of emissions (e.g. factories, utilities), because the former is usually capable of accounting for up to $100 \%$ of total emissions, while downstream schemes usually only cover significantly less. In addition, carbon dioxide equivalents $\left(\mathrm{CO}_{2} \mathrm{eq}\right)$ are an easy way to allow the inclusion of all GHG.

Socially just carbon markets should have absolute volume caps in line with the $2{ }^{\circ} \mathrm{C}$ target in order to comply with inter-generational justice. As global warming is determined by GHG concentrations in the atmosphere, absolute emission amounts matter. Hence, in order to prevent dangerous global warming and protect future generations from excessive burdens, absolute volume targets and caps are indispensable. Intensity targets (e.g. emissions per product or per unit GDP), in contrast, allow for absolute emission volume increases even at low emission rates, in the case that the total production output increases. Concerning a number target, while an exact global climate policy goal is still difficult to justify, scientific evidence (IPCC 2014) - and even the political will at the Copenhagen Climate Summit - sufficiently supports the notion of the $2^{\circ} \mathrm{C}$ target being able to at least protect future generations from the worst consequences of global warming. As a consequence, industrialized countries would have to reduce their emissions by 2540\% by 2020 and by 80-95\% by 2050 (IPCC 2014). The Budget Approach (WBGU 2009) calculates only 600 million tons of $\mathrm{CO}_{2}$ eq emissions to be acceptable between 2010 and 2050 in order to still achieve this target. Equality arguments would then call for equal rights to the use of natural resources for each citizen of the world. If, as a supplement, the polluter-pays-principle would be applied, the historic responsibility for climate change would even call for further redistribution in favor of the developing world. Based on these ideas, theoretically, national carbon caps could be calculated and justified on a social justice basis. However, as the distributional consequences of such an approach would be sudden and dramatic, intra-generational justice calls 
for a more moderate transitional approach such as Contraction and Convergence (Meyer 2000). Over a specified period of time, the total number of emissions allowances would contract from the status quo to the target level and the distribution of emission rights would converge to equal per capita rights. However, it has to be kept in mind that even dramatic re-distributional burdens could also be alleviated by the well-targeted spending of carbon pricing revenues.

The initial allocation of emissions allowances should be done by auctioning alone, because only then would the design comply with the polluter-pays-principle and result-based justice in transfer and acquisition as well as in allocation. Mutual compensation for efforts would be provided, the resulting distribution would be according to individual claims and polluters would have to pay resource use costs fully. In free allocation schemes, in turn, the scarcity rents introduced by the cap are transferred to polluters, who can make windfall profits it they can pass on costs to consumers. However, if all allowances are sold, major parts of the scarcity rents remain with the government and can be used for multiple purposes.

Depending on the exact design of revenue spending, it serves inter- and intra-generational justice as well as the equality criterion to a differing extent. First, they can be used for lowering distortionary taxes, create a double dividend, and increase overall efficiency (Bovenberg 1999), thus mainly serving national intra-generational justice. Second, investing revenues in additional climate mitigation measures would primarily promote inter-generational justice as future global warming burdens would be further reduced. Third, using revenues for adaptation measures or damage compensation in countries or regions that suffer most from climate change would especially foster international intra-generational justice. Fourth, compensating low-income for higher energy costs or even cushioning cost increases for selected industries in order to prevent carbon leakage would cater to national intra-generational justice. Fifth, the Sky Trust proposal (Barnes 2001), suggests reimbursing revenues to citizens on an equal per capita basis; this follows the principle of equal entitlements to natural resource use for all citizens and would also serve international intra-generational justice. In general, full auctioning combined with a well-designed redistributional scheme addresses social justice issues most adequately. 
While banking - the saving of early reduction credits for later use - might even foster intergenerational justice, borrowing - the present use of future reductions - may be in violation of this criterion; offsets might even serve social justice. While both borrowing and banking reduce compliance costs and serve intra-generational justice, borrowing allowances for compensating present emissions without reducing emission in the future increases GHG concentrations in the atmosphere and hurts future generations. Banking could even additionally profit future generations if banked allowances are not used in the future. While bad offsets violate several social justice criteria, high quality offsets may serve inter-generational as well as intragenerational justice as compliance cost reductions, money, and technology and know-how transfers are possible. Quantity limits to high quality offsets are dispensable for the same reasons and in addition the polluter-pays-principle fully applies anyway.

Market design should guarantee easy and equal access for all emitters, at best use price floors but not price ceilings, and implement short compliance periods in order to comply with inter- and intra-generational justice, the polluter-pays-principle, and result-based justice in transfer and acquisition. Equal access to the market should be granted in order not to disadvantage specific groups or individuals and follow the equality principle. Intervening into the market by increasing the amount of allowances, if the prices hits a certain level (safety valves) jeopardizes intergenerational justice, if extra allowances are not ex ante included in the cap. It also violates the polluter-pays-principle and the result-based justice in transfer and acquisition. While at first glance price ceilings seem to protect present generations from excessive cost burdens and thus serve national intra-generational justice and price floors would guarantee revenues usable for redistributional measures even in the case of a lack of scarcity, price corridors prevent the market from exhibiting the real scarcity of the resource and from making the polluter fully pay, thus interfering with inter-generational justice, polluter-pays-principle, and the result-based justice in transfer and acquisition. Using auction revenues for compensating excessive burdens and reducing the cap or internationally linking carbon markets would be preferable solutions. Compliance periods should be short, because this allows for short-term control over reduction achievements and provide opportunities for immediate penalties and ex-post emission 
compensation in the case of non-compliance. This would significantly foster inter-generational justice. However, trading periods can be long, if supplemented by short-term submission requirement for major parts of used emissions rights.

Reliable monitoring and quenching penalties are a necessary component of intergenerationally just carbon markets, which also make polluters fully pay, and comply with resultbased justice in transfer and acquisition. In emission markets, authorities have to check whether emitters can compensate each and every unit of emissions by an emission allowance in its hold. Only this guarantees that emissions at one point are compensated for by emission reductions at another point, which, in turn, would lead to compliance with the overall cap. Continuous emissions monitoring or verified self-reporting both seem to be sufficiently reliable. In the case of non-compliance, severe penalties, ex post, punish polluters for breaching the rules; ex ante, such penalties discourage emitters from non-compliance. Only this would safeguard future generations, make polluters fully pay, and comply with result-based justice in transfer and acquisition. In addition, those criteria call for ex pot compensation of allowance shortages. Equality demands identical fine levels for all non-complying polluters.

Protective measures such as border (tax) adjustments are be reasonable from an intragenerational international and inter-generational justice as well as from an equality perspective. Ambitious domestic carbon markets may suffer from leakage, if competitors do not use comparably stringent policies. Leakage can be prevented by either creating an ambitious common market of all major competitors or protecting ambitious climate policy countries by implementing border (tax) adjustments or making domestic carbon markets less stringent. While the first alternative is obviously the most desirable - though politically the most difficult - from the perspective of e.g. equality, inter-generational justice, and the polluter-pays-principle, and the last is clearly unacceptable for the same reasons, border (tax) adjustment levels the playing field for domestic emitters and thus caters to the equality criteria, international intra-generational justice, and inter-generational justice.

Against the background of these concrete design recommendations, to what extent do current carbon market in the EU and the US comply with social justice criteria? 


\section{How fair are current carbon markets?}

\subsection{EU Greenhouse Gas Emissions Trading Scheme (EU ETS)}

The EU ETS, still the biggest carbon market in the world, started operation in 2005, but has since been significantly revised when moving from Phase I (2005-2007), via Phase II (2008-2012) and III (2013-2020) to the [planning stage of Phase IV (2021-2028) (EU Com 2013, EU Com 2014). The EU ETS complies fully with the social justice criteria for bindingness, but only partly for coverage, although recent reforms have broadened the latter. It is a mandatory scheme that mainly covers $\mathrm{CO}_{2}$ emissions from big stationary emitters such as utilities and energy intensive industries downstream. While air transport from, to, and within the EU should have been included from 2012 onwards, due to international controversies, only flights within the EU are covered yet. Other major emitting sectors such as ground transport and households, however, are deliberately excluded addition. In addition, the EU ETS covered $\mathrm{CO}_{2}$ only in the first two phases (2005-2007, 2008-2012), but since 2013 additional GHG such as $\mathrm{N}_{2} \mathrm{O}$ and PFCs can be included. Still, major pollutants such as methane remain unregulated under the EU ETS, so that overall the EU ETS continues to only comprises around $45 \%$ of EU GHG emissions. Nevertheless, while the social justice criterion for coverage is not fully fulfilled by the EU ETS alone, it has to be taken into account that additional, even partly market-based policy instruments such as energy taxes and energy efficiency standards cover major parts of the non-ETS sectors. Reasons for limited coverage under the EU ETS might be problems of measuring or respective EU or national targets and regulation under different schemes such as eco taxes or energy standards. But still, significant social justice problems remain as not all pollutants and polluters are treated on an equal basis, cost burdens are not shared fairly within the present generation, future generations may face unnecessary burdens, and not all polluters pay their fair share of using natural resources.

The EU ETS increasingly complies with social justice criteria for the cap size, but still lags behind the necessities. While the annual absolute volume cap was 2298.5 million metric tons of $\mathrm{CO}_{2}$ in Phase I, allowing an increase of emissions by $8.3 \%$ compared to the actual emissions in 2005, in Phase II, the annual emissions budget was only 2086.5 million tons, representing a 5.9\% 
decrease in allowed emissions compared to 2005 (Ellerman/Joskow 2008). In Phase III, a European cap replaces the National Allocation Plans (NAP) of the first two phases. In addition, starting with average total emissions of 2008-2012, the EU cap is being reduced by $1.74 \%$ annually, which sums up to a $21 \%$ reduction by 2020 compared to 2005 emissions. The aviation cap is at a constant 210 million tons until 2020. After 2020, the total allowance amount is intended to decrease by $2.2 \%$ in order to achieve a $43 \%$ emission reduction by 2030 compared to 2005 levels. As a shortterm measure against low carbon prices the $\mathrm{EU}$ has been holding back of 900 million tons of $\mathrm{CO}_{2}$ allowances from the years 2014-2016; these allowances will be transferred to the Market Stability Reserve (MSR), available from 2019 onwards. Hence, there is a significant improvement in terms of allowed emissions from Phase I to IV, improving also the compliance with social justice criteria. Still, considering the reduction necessity for industrialized countries (25-40\% by 2020 , 80 90\% by 2050), it remains questionable if the EU ETS effort is big enough to help the EU to fulfill its share of responsibility for achieving the $2^{\circ} \mathrm{C}$ target.

The social justice criteria for the validity of emission rights and the initial allocation are increasingly fulfilled after recent reforms, but still many flaws persist. Using $\mathrm{CO}_{2}$ equivalents, one EU allowance (EUA) authorizes polluters to emit one ton of $\mathrm{CO}_{2} \mathrm{eq}$ in a given year. While in Phase I and II, 95\% and 90\% of all allowances had to be handed out for free, from Phase III onwards utilities have to buy all their emission rights; with the exemption of low GDP member states, which can provide $60 \%$ from free. The share of free allocation to energy intensive industries is supposed to decrease steadily from 80\% in 2013 to 30\% in 2020 and $0 \%$ in 2027; however, major exemptions for industries under the threat of carbon leakage have been granted so far, allowing $100 \%$ free allocations even beyond 2020 . The aviation sector must only buy $15 \%$ of their emission allowances. New entrants receive allowances for free from a special reserve, while in the case of facility shut downs allowances have to be returned. Banking and borrowing within compliance phases are unlimited. But across compliance phases, banking had not been allowed from Phase I to II, but was made possible for the following phases; cross-period borrowing remains prohibited. Limitation on offset credit use have become more stringent over time. While there were not limits in Phase I, since Phase II credits from nuclear and land use are excluded. 
Since the start of Phase III, in addition, new credits are only accepted from projects in Least Developed Countries (LDC), industrial gas credits are excluded, and since 2015 no credits from the Kyoto I period are accepted. Also, since the Phase II, the use of credits must not exceed $50 \%$ of total EU reductions between 2008 and 2020 (approx. 1.6 billion tons). From Phase IV onwards, any international credits will be excluded. Hence, while social justice criteria are increasingly met in Phase III and IV, particularly the continuous use of free allocations remains questionable.

Auctioning off major parts of EU allowances allows for using revenues for social justice purposes; but EU regulations only earmark 50\% of these revenues to energy and climate policy use, leaving the rest up to member states' decisions. This leaves a lot of leeway to national member states. While many south-eastern European countries only use the earmarked 50\% for climatechange-related spending, Germany established the Special Energy and Climate Fund, which transfers almost $100 \%$ of the revenues to national and international climate financing, France, dedicates almost $100 \%$ to retrofitting social housing, and Finland, invests $100 \%$ climate action in development cooperation (Germanwatch 2013). This variety of revenue utilization makes an assessment difficult. However, while energy efficiency programs also lower energy costs for current generations and development aid might help vulnerable regions, intra-generational justice could be more directly targeted e.g. by cost compensations for poor households or adaptation measures in most vulnerable areas (Caney/Hepburn 2011). This is particularly true, as environmental and economic goals are already targeted by capping emissions and generating carbon prices.

The EU ETS market design complies with social justice criteria to a large extent. The allowance market is equally open to all covered facilities and interested parties. Allowances can be bought from two major auction, EEX in Leipzig and ICE in London, in a non-discriminatory procedure. While compliance periods are one year, trading periods have been steadily increase from 3 via 5 to 8 years, trying to increase the long-term planning reliability for abatement investment. For price control, the EU decided on a Market Stability Reserve (MSR) from 2019 onwards for addressing market imbalances, where measures such as cap reductions or international linkages would be preferable from the social justice perspective (Lerch 2015).

The EU ETS monitoring scheme complies entirely with the respective social justice criteria. 
All installation have to file annual emission reports according to harmonized EU rules. Reports are verified by accredited verifiers. If allowed emissions are exceeded, facilities have to cover excess emissions and pay a penalty of 100 Euro per ton from Phase III (40 Euro in Phase I and II). Also, the names of facilities not meeting their obligations are published.

Overall, while having started poorly, after the recent reforms the EU ETS complies with major social justice criteria. Still, much leeway for improvements exist especially in the areas of coverage, cap size, initial allocation, revenue spending, and price control.

\subsection{The Regional Greenhouse Gas Initiative (RGGI)}

RGGI was the first large-scale, multi-state carbon market in the US and started in 2009. It now covers nine North Eastern states’ $\mathrm{CO}_{2}$ emissions. Already in Phase 1 (2009-2014), RGGI underwent a fundamental reform before entering into Phase II (2015-2020) (RGGI 2013, Rudolph/Lerch 2012).

RGGI fulfills social justice criteria for bindingness but only partly for coverage. RGGI is mandatory for all participating sources, but it only covers $\mathrm{CO}_{2}$ emissions from combustion in big utilities (> $25 \mathrm{MW}$ ) downstream. While industry emissions are of minor relevance (in New York State e.g. only 7\% of all energy related $\mathrm{CO}_{2}$ emissions), RGGI still neither covers emissions from other sectors such as transport or households nor does it include non- $\mathrm{CO}_{2} \mathrm{GHG}$ emissions. Again, other policies might step in and there are problems of measurement, but still similar social justice problems as in the case of the EU ETS remain.

RGGI increasingly fulfills the social justice requirement after the 2014 reform. While the cap was initially set at a generous constant 188 million US tons of $\mathrm{CO}_{2}$ per year from 2009 to 2014 (4\% above average 2002-2004 emissions) and a reduction path of $2.5 \%$ per year in Phase II, the tremendous oversupply led to a cap reduction by more than 50\% in 2014. For 2014 the cap was set at 91 million US tons and it then enters the yearly reduction dynamics of 2.5\% until 2020, resulting in a total emission reduction of more than two thirds compared to 2002-2004 emissions, a period, when RGGI region emissions already did not significantly exceed 1990 levels.

Social justice criteria for the initial allocation of allowances and allowance validity are largely fulfilled in the RGGI case. While RGGI rules only oblige participating states to auction off at 
least $25 \%$ of all allowances, the actual average auction rate is higher than $90 \%$. New entrants have to buy all their allowances, and there are no specific rules for returning unused allowances in the case of facility shut-downs. Banking is unlimited within and across compliance periods; however, Phase II caps were adjusted for Phase I banked allowances in the 2014 reform. Borrowing is prohibited. Offset use is limited to $3.3 \%$ of facility emissions and to additional and sustainable $\mathrm{CH}_{4}, \mathrm{SF}_{3}$, and $\mathrm{CO}_{2}$ project credits from agriculture, forestry, waste treatment, and building energy efficiency within the US. While the early program allowed the use of Kyoto credits if allowance prices exceed 10 US\$, since the 2014 reform no such credits are accepted.

Revenue spending so far focusses on climate action and budget consolidation, thus mainly serving inter-generational justice. The auctioning rules oblige participating states to invest all revenues from the $25 \%$ mandatory auctioning share into climate and energy measures. However, the real auction share of approx. 90\% leaves a lot of leeway to participating states. Around two thirds of all revenues are used for climate and energy programs, 15\% go to the support of disadvantaged communities, and $15 \%$ to budget consolidation. While obviously the focus is on inter-generational justice, efficiency programs and cost compensation also serves intra-generational national justice.

RGGI's market design also increasingly complies with social justice criteria, but is still flawed with market intervention mechanisms. The allowance market is equally open to all covered entities and interested parties. Allowances can be bought from non-discriminator state auctions and several secondary markets such as the Chicago Climate Futures Exchange (CCFE). Control periods are 3 years, after which $100 \%$ of emissions have to be covered by allowances; but in addition, after the first 2 years of each control period $50 \%$ of needed allowances must be held in stock, providing extra safety in terms of compliance. For price control, RGGI implemented a floor price of US\$ 1.89, which have increased annually by 2.5\%. In addition, the 2014 reform implemented a Cost Containment Reserve (CCR) populated with 10 million allowances taken from the overall budget and refilled only if necessary. CCR allowances are auctioned if the carbon price exceeds US\$ 4 (2014), 6 (2015), 8 (2016), or 10 (2017); after 2017 trigger prices increase by 2.5\% per year. While the CCR replaces earlier price ceilings, still, better options for limiting price fluctuation such as international linkages are available. 
RGGI's monitoring scheme complies entirely with the respective social justice criteria. Emissions data is continuously provided by the US Environmental Protection Agency (EPA) based on 1995 Clean Air Act (CAA) rules. Allowances, emissions, and transfers are recorded in the $\mathrm{CO}_{2}$ Allowance Tracking System (COATS), which is even open to the public. In the case of non-compliance, fines of up to US\$25,000 apply in addition to a 3-for-1 excess emissions coverage requirement.

Overall, RGGI also complies with major social justice criteria. In particular, the 2014 reform accomplished major improvements. But still, coverage, revenue use, and market design could be improved.

\section{Conclusions}

We are convinced that social justice, being a founding principle of sustainable development and becoming more and more important due to carbon pricing driven energy price increases, has to play a key role in the design of sufficiently ambitious and politically feasible carbon pricing schemes. Carbon pricing itself, also should be the main pillar in sustainable climate policy not only because it provides emission reductions at lowest cost to society and thus minimizes the burden to current generations, but also because considering social justice issues in carbon pricing design is possible. However, research and policy have not adequately considered social justice in carbon pricing design.

Here, as a first step, we have provided a framework for designing socially just carbon markets and for evaluating existing programs on social justice grounds. We have derived concrete design recommendations from rather general and sometimes even vague social justice concepts; we have shown that carbon pricing can easily serve social justice purposes if well designed; and we have evaluated early EU and US markets, the EU Emissions Trading System (EU ETS) and the Regional Greenhouse Gas Initiative (RGGI), on these grounds. Such markets started poorly, but after recent reforms, in addition to becoming more environmentally effective and economically efficient, they increasingly comply with social justice criteria. Still, of course, both programs can be improved. The key design elements for improvements are coverage, cap size, the initial allocation, revenue spending, and price control mechanisms. 
As more carbon markets have emerged recently e.g. in California, China, Japan, New Zealand, and South Korea, evaluating those from a social justice perspective is certainly a promising endeavor for future research. California's Cap-and-Trade Program seems to be a particularly interesting case, as much energy has been spent on designing auction proceeds investment plans (http://www.arb.ca.gov/cc/capandtrade/auctionproceeds/auctionproceeds.htm distribution), one of the key design elements for targeting social justice. Also, as linking domestic carbon markets can be considered on important complement to global climate policy, the social justice implications of such linking projects is a worthwhile subject for further studies with e.g. the already established between California-Québec-linkage as an empirical example. Not least, adjusting and applying our evaluation framework to carbon taxation might further strengthen the case for sustainable market-based climate policy, as it has already been shown here that carbon pricing can be designed in a way to effectively foster social justice.

\section{References}

Barnes, P. (2001), Who owns the Sky? Washington: Island Press.

Bovenberg, L.A. (1999), Green Tax Reforms and the Double Dividend, International Tax and Public Finance 6, 421-443.

EU Com (2013), The EU Emissions Trading System (EU ETS), Brussels.

EU Com (2014), A policy framework for climate and energy policy in the period 2020 to 2030. Brussels.

Fankhauser, S., Hepburn, C. (2010), Designing carbon markets Part I+II, Energy Policy 38, 43634370, 4381-4387.

Germanwatch (2013), Using EU ETS Auctioning Revenues for Climate Action. Berlin

Hayek, F.A. von (1996), Die Anmaßung von Wissen, Tübingen: Mohr.

Harris, P.G. (2010), World Ethics and Climate Change, Edinburgh: Edinburgh University Press.

Heindl, P., Schüßler, R., Löschel, A. (2014), Ist die Energiewende sozial gerecht? Wirtschaftsdienst DOI: 10.1007/s10273-014-1705-7

Helmstädter, E. (1997), Über die Gerechtigkeit gerechter Regeln, in M. Held (ed): Normative Grundfragen der Ökonomik, Frankfurt: Campus. 
IPCC (2014), Climate Change 2014 - Synthesis Report. Geneva

Kahneman, D., Knetsch, J.L., Thaler, R. (1986) Fairness as a Constraint on Profit Seeking, American Economic Review 75, 728-741.

Krebs, A. (ed) (2000), Gleichheit oder Gerechtigkeit, Frankfurt: Suhrkamp.

Lerch, A. (2011), $\mathrm{CO}_{2}$-Emissionshandel - effizient oder gerecht? Zeitschrift für Sozialökonomie 48, 39-47

Lerch, A. (2015), Emissionshandel reloaded, Ökologisches Wirtschaften 4/2015, 12.

Marx, K. (1972), Kritik des Gothaer Programms, in K. Marx, F. Engels, Werke Vol. 19, Berlin.

Meyer, A. (2000), Contraction and Convergence, Totnes: Green Books.

Nozick, R. (1974), Anarchie, Staat, Utopia, Moderne, München: Verlags Gesellschaft.

Ott, K., Döring, R. (2004), Theorie und Praxis starker Nachhaltigkeit, Marburg: Metropolis.

Ott, H.E., Sachs, W. (2002), The Ethics of International Emissions Trading, in L. Pinguelli-Rosa, M. Munasinghe (ed), Ethics, Equity and International Negotiations on Climate Change. Cheltenham: Edward Elgar, 159-178.

Ranson, M., Stavins, R.N. (2015), Linkage of greenhouse gas emissions trading systems, Climate Policy DOI: 10.1080/14693062.2014.997658.

Rawls, J. (1971), A Theory of Justice. Cambridge: Harvard University Press.

RGGI (2013), Model Rule - Revised 2013. New York

Rudolph, S., Lerch, A. (2012), Treibhausgas-Emissionshandel in den USA. Zeitschrift für Umweltpolitik \& Umweltrecht, 35(4), 421-449

Rudolph, S., et al. (2012): Towards sustainable carbon markets. In: Kreiser, L. et al. (Eds.): Carbon Pricing, Growth and the Environment. Cheltenham/Northampton (Edward Elgar), 167-183.

Schleich, J. et al. (2014), Citizens' perceptions of justice in international climate policy, Climate Policy DOI: 10.1080/14693062.2014.979129.

WCED (1987), Our Common Future, Oxford: Oxford University Press.

WBGU (2009), Solving the climate dilemma, Berlin.

World Bank (2015), State and Trends of Carbon Pricing, Washington DC. 
${ }^{\mathrm{i}}$ Discussion paper presented at the $16^{\text {th }}$ Global Conference on Environmental Taxation (GCET 16), September 23-26, 2015, University of Technology, Sydney, Australia.

ii Dr. Sven Rudolph, Associate Professor, Graduate School of Economics, Kyoto University, Japan; Dr. Achim Lerch, Professor, Hessian University of Cooperative Education (Hessische Berufsakademie), Germany. Contact: rudolph@econ.kyoto-u.ac.jp. 